\title{
Cellular Bases of Barbiturate and Phenytoin Anticonvulsant Drug Action
}

\author{
Robert L. Macdonald and Michael J. McLean \\ Department of Neurology, University of Michigan Medical Center, \\ Ann Arbor, Michigan
}

Although anticonvulsant drugs are the
mainstay of therapy for epilepsy, their
mechanisms of action remain uncertain for
several reasons. First, most anticonvulsant
compounds have been shown to have mul-
tiple physiological, biochemical, and phar-
macological actions. It has been difficult,
therefore, to determine which specific drug
actions produce clinical effects. Second,
investigation has often been performed on
isolated peripheral or invertebrate neuronal
or muscle preparations or on neurons in the intact vertebrate central nervous system. In the former case, the number of drug actions that can be studied is limited, since the pharmacology of these cells is quite unlike that found in the vertebrate central nervous system. In the latter case, the preparation is technically difficult to study and, therefore, limited experimental control is possible. Third, investigators have identified single actions of anticonvulsants and suggested a role in anticonvulsant action without determining if the drug effect is produced at concentrations achieved in the central nervous system during clinical use. Finally, anticonvulsants are often studied at concentrations achieved in serum during clinical use. However, for anticonvulsants that are protein bound, it is important to use therapeutic free-serum concentrations, since cerebrospinal fluid drug levels reflect free, not total, serum drug concentrations.

We have employed an in vitro mammalian neuronal preparation to study anticonvulsant drug action. Mouse spinal cord neurons in primary dissociated cell culture develop electrical excitability, synaptic connectivity, and postsynaptic chemosensitivity to a variety of putative neurotransmitters $(1,2)$. Stable intracellular recordings can be made from individual neurons for several hours, and drugs and neurotransmitters can be applied by iontophoresis, local pressure ejection, or superfusion of the entire culture. Furthermore, with this neuronal preparation, it is possible to apply known concentrations of anticonvulsants directly to neurons in serum-free medium, thus obviating many pharmacokinetic problems of whole animal studies (serum protein binding, blood-brain barrier, and drug metabolism). In this paper we will review our investigations of barbiturate mechanisms of action and present recent studies of phenytoin actions.

\section{Barbiturate Actions}

Long-acting barbiturates such as phenobarbital $(\mathrm{PhB})$ and mephobarbital are useful as chronic anticonvulsants since they have minimal sedative action at therapeutic concentrations. Intermediate- and short-

Address correspondence to Dr. Macdonald at Neuroscience Laboratory Building, 1103 East Huron, Ann Arbor, Michigan 48109. 
acting barbiturates such as pentobarbital (PB), thiopental, or amobarbital are also effective anticonvulsants, but cannot be used clinically due to their prominent sedative effects. What is the basis for this difference in action among these barbiturates?

To assess barbiturate actions on physiological neuronal activity, we determined the effect of $\mathrm{PhB}$ and $\mathrm{PB}$ on normal spontaneous activity (3) (Fig. 1). Spontaneous activity of spinal cord neurons in cell culture consists of a random admixture of excitatory and inhibitory postsynaptic potentials and spontaneous action potentials. Both $\mathrm{PhB}$ and PB produced dose-dependent reduction in spontaneous activity, resulting in an increasing percentage of quiescent neurons at increasing barbiturate concentrations. $\mathrm{PB}$ was substantially more potent than $\mathrm{PhB}$, increasing the percentage of quiescent neurons from 0 to $100 \%$ over concentrations of $100-500 \mu M\left(E_{50}\right.$, $250 \mu M)$. PhB produced a similar effect at higher concentrations of 500-2,500 $\mu \mathrm{M}$ $\left(\mathrm{ED}_{50}, 900 \mu M\right)$. PB produces anesthesia at brain levels of about $100-200 \mu M$, and thus production of $20-30 \%$ quiescent neurons should correlate with anesthesia. Anticonvulsant action would have to occur at much lower concentrations to avoid sedative toxicity.

As a model of anticonvulsant action, we investigated the effect of barbiturates on bicuculline (BICUC)-induced paroxysmal activity (3). BICUC is a convulsant that antagonizes GABA responses $(4-6)$ by competing with GABA to bind to GABA receptors $(7,8)$. In addition, at somewhat
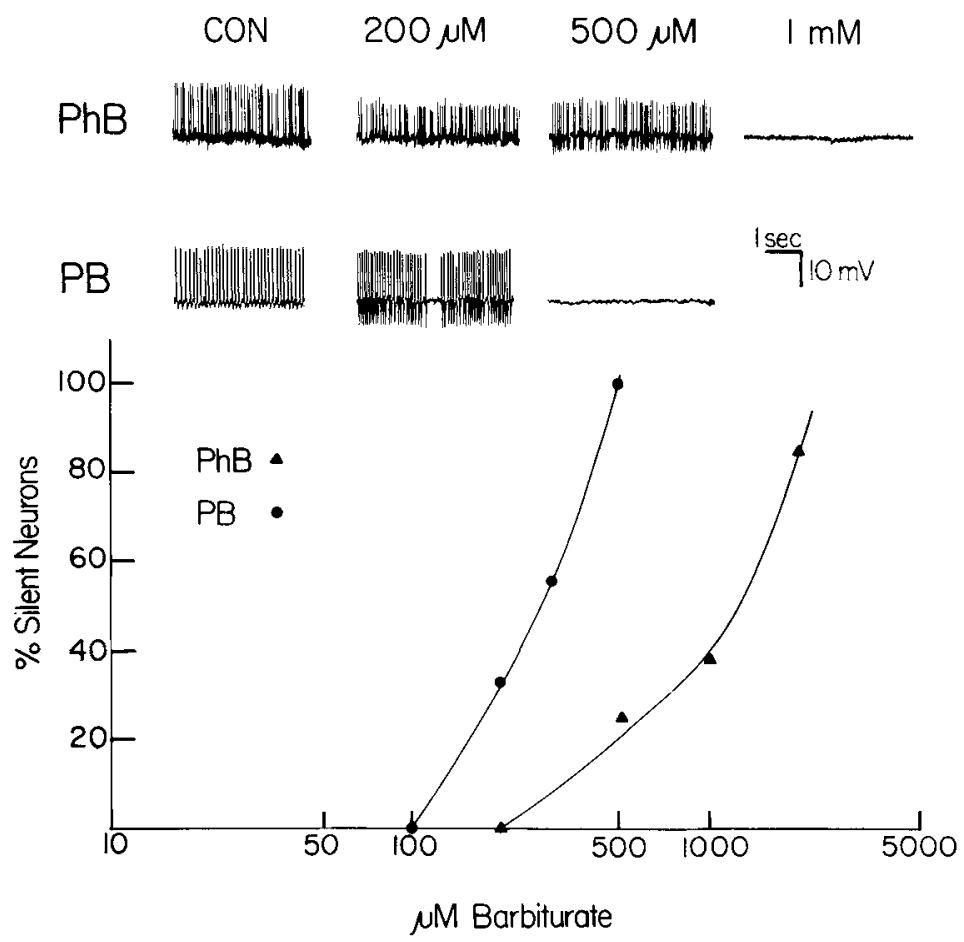

FIG. 1. Phenobarbital ( $\mathrm{PhB}$, triangles) and pentobarbital (PB, circles) reduced spontaneous activity. Spontaneous activity was recorded from spinal cord neurons in control medium (phosphate buffered saline, PBS) and in PBS containing barbiturates. Specimen records are intracellular recordings made with glass micropipettes filled with $4 M$ potassium acetate displayed on a rectilinear polygraph. Each point in the graph represents the mean $\%$ silent neurons obtained from 4 to 7 neurons (total of 22 for PB and 18 for PhB). CON, control. (From Schulz and Macdonald (3), with permission.) 
higher concentrations, BICUC reduces membrane potassium conductance $(9,10)$. When added to medium bathing spinal cord neurons in cell culture, BICUC produces large, randomly occurring depolarizations that evoke volleys of action potentials $(5,9)$. These paroxysmal depolarizing events (PDE) appear to be similar to convulsantinduced paroxysmal bursting in spinal motor neurons (11) and to convulsantinduced paroxysmal depolarization shifts recorded in cortical neurons $(12,13)$. When BICUC was added at $40 \mu M$, all neurons developed PDE (9). Both PhB and PB (25-500 $\mu M$ ) abolished PDE in a dosedependent fashion (Fig. 2). PB (ED ${ }_{50}, 75$ $\mu M$ ) was slightly more potent than $\mathrm{PhB}$ $\left(\mathrm{ED}_{50}, 90 \mu M\right)$, but both drugs restored normal spontaneous activity. Therapeutic anticonvulsant serum levels of $\mathrm{PhB}$ vary from about 40 to $160 \mu M(10-40 \mu \mathrm{g} / \mathrm{ml})$, but since $\mathrm{PhB}$ is about $50 \%$ protein bound, free $\mathrm{PhB}$ levels would be in the range of about 20 to $80 \mu M$. Thus, $\mathrm{PhB}$ (and $\mathrm{PB}$ ) reversed convulsant-induced paroxysmal activity and restored normal spontaneous activity at clinically relevant concentrations.

What are the bases for barbiturate anticonvulsant, sedative-hypnotic, and anesthetic actions? Barbiturates have multiple actions on both synaptic and nonsynaptic membranes (Table 1). Barbiturates act (a) postsynaptically to enhance GABAergic inhibition $(3,14-19)$, to reduce glutaminergic $(15,17-19)$ and cholinergic $(20$, 21) excitation, and to directly activate membrane GABA receptor-coupled chloride ion channels $(3,15,19)$; (b) presynaptically to reduce release of neurotransmitters $(22-25)$ including GABA $(26,27)$, glutamate $(27-29)$, aspartate $(28-30)$, acetylcholine $(28,31-34)$, and norepinephrine $(35)$; and

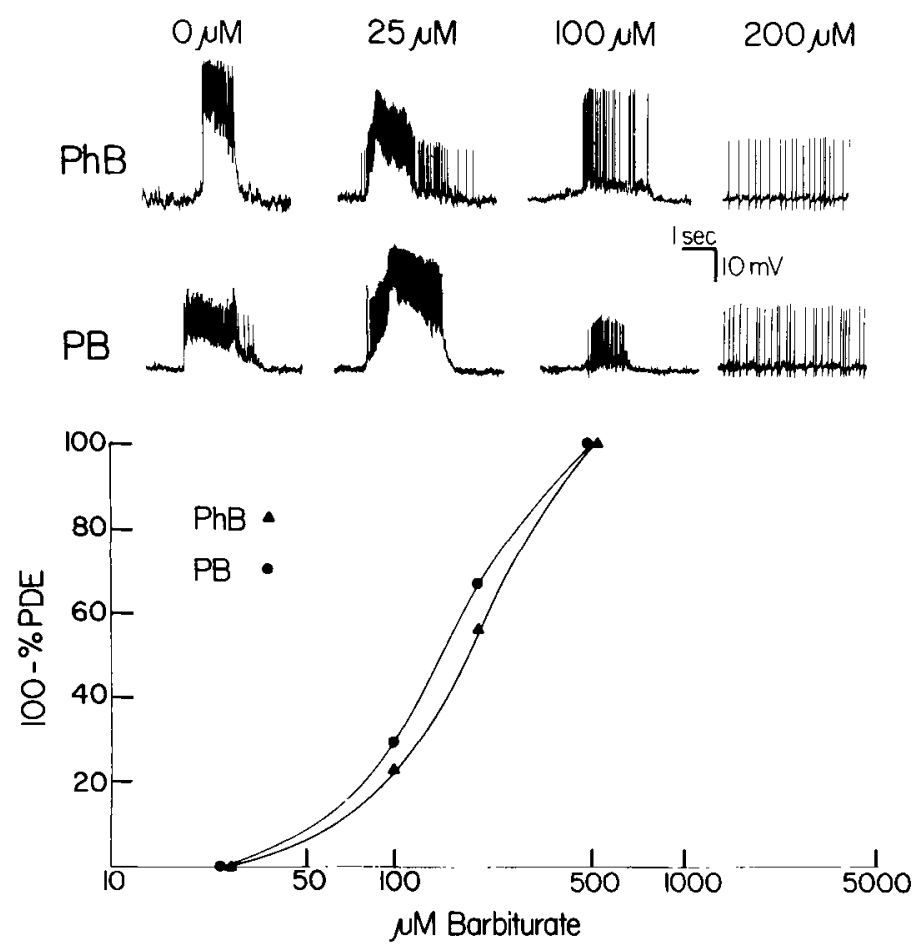

FIG. 2. PhB and PB abolished bicuculline (BICUC)-induced paroxysmal depolarizing events (PDE). When 40 $\mu M$ BICUC was added to PBS, $100 \%$ of spinal cord neurons developed PDE. See legend to Fig. 1 for recording details, symbols, and abbreviations. (From Schulz and Macdonald (3), with permission.) 
TABLE 1. Barbiturate actions

\begin{tabular}{l} 
Alteration of post synaptic neurotransmitter action \\
Enhancement of GABA-mediated inhibition \\
Antagonism of excitatory synaptic transmission \\
Direct enhancement of membrane chloride ion conductance \\
Reduction of presynaptic calcium entry and neurotransmitter release \\
Reduction of nonsynaptic membrane sodium and potassium ion conductances \\
\hline
\end{tabular}

(c) nonsynaptically to reduce sodium and potassium conductances (36-38).

To investigate postsynaptic barbiturate actions on neurotransmitter responses, we determined the effect of barbiturates on GABA, glycine, $\beta$-alanine, and glutamic acid responses evoked on spinal cord neurons $(3,18,19)$. Both $\mathrm{PhB}(20-500 \mu M)$ and $\mathrm{PB}(10-400 \mu M)$ augmented GABA responses at low concentrations without altering glycine or $\beta$-alanine responses, with PB having a slightly lower $\operatorname{ED}_{50}(50 \mu M)$ than $\mathrm{PhB}(75 \mu M)$ (Fig. 3). Both $\mathrm{PhB}$ and PB antagonized glutamic acid responses at barbiturate concentrations effective in augmenting GABA responses̀. Thus, both

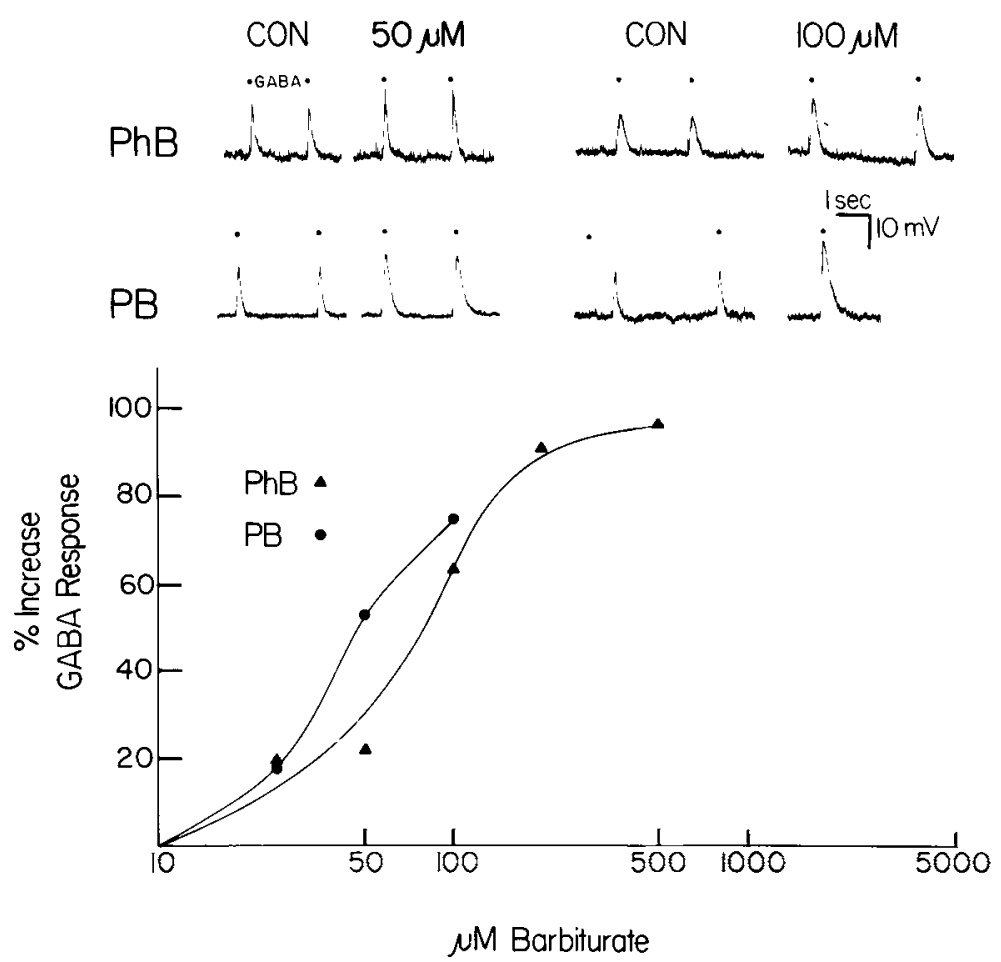

FIG. 3. PhB and PB augmented postsynaptic GABA responses. Intracellular recordings were made with glass micropipettes filled with $3 M \mathrm{KCl}$ from spinal cord neurons bathed in PBS containing $10 \mathrm{~m}^{2} \mathrm{Mg}^{2+}$ to suppress spontaneous activity. GABA was applied by iontophoresis for $100 \mathrm{~ms}$ and barbiturates were applied by local pressure injection from large-tipped glass pipettes. GABA responses were depolarizing due to intracellular chloride leak from the recording micropipettes. Each point on the plot represents the average augmentation of GABA responses on three to eight spinal cord neurons with two to four trials per neuron ( 33 trials for PhB and 15 trials for PB). See legend to Fig. 1 for symbols and abbreviations. (From Schulz and Macdonald (3), with permission.) 
$\mathrm{PhB}$ and $\mathrm{PB}$ modulated postsynaptic amino acid responses at concentrations which reversed $B I C U C$-induced $P D E$ and which are achieved in the central nervous system when serum barbiturate concentrations are therapeutic. It is therefore likely that barbiturates have anticonvulsant action due to augmentation of postsynaptic GABAergic inhibition, as well as to antagonism of postsynaptic glutaminergic excitation.

In addition, both $\mathrm{PhB}$ and $\mathrm{PB}$ were shown to reduce calcium-dependent action potential duration (39) and to increase membrane chloride ion conductance $(3,19)$ (Fig. 4). Release of neurotransmitter is calcium dependent (40), requiring entry of calcium through voltage-dependent presynaptic calcium channels $(40-42)$. Since barbiturates reduce calcium-dependent action potential duration (39) and calcium uptake by synaptosomes $(43-45)$, it is probable that they block neurotransmitter release by reducing presynaptic voltage-dependent calcium ion entry. The direct increase in
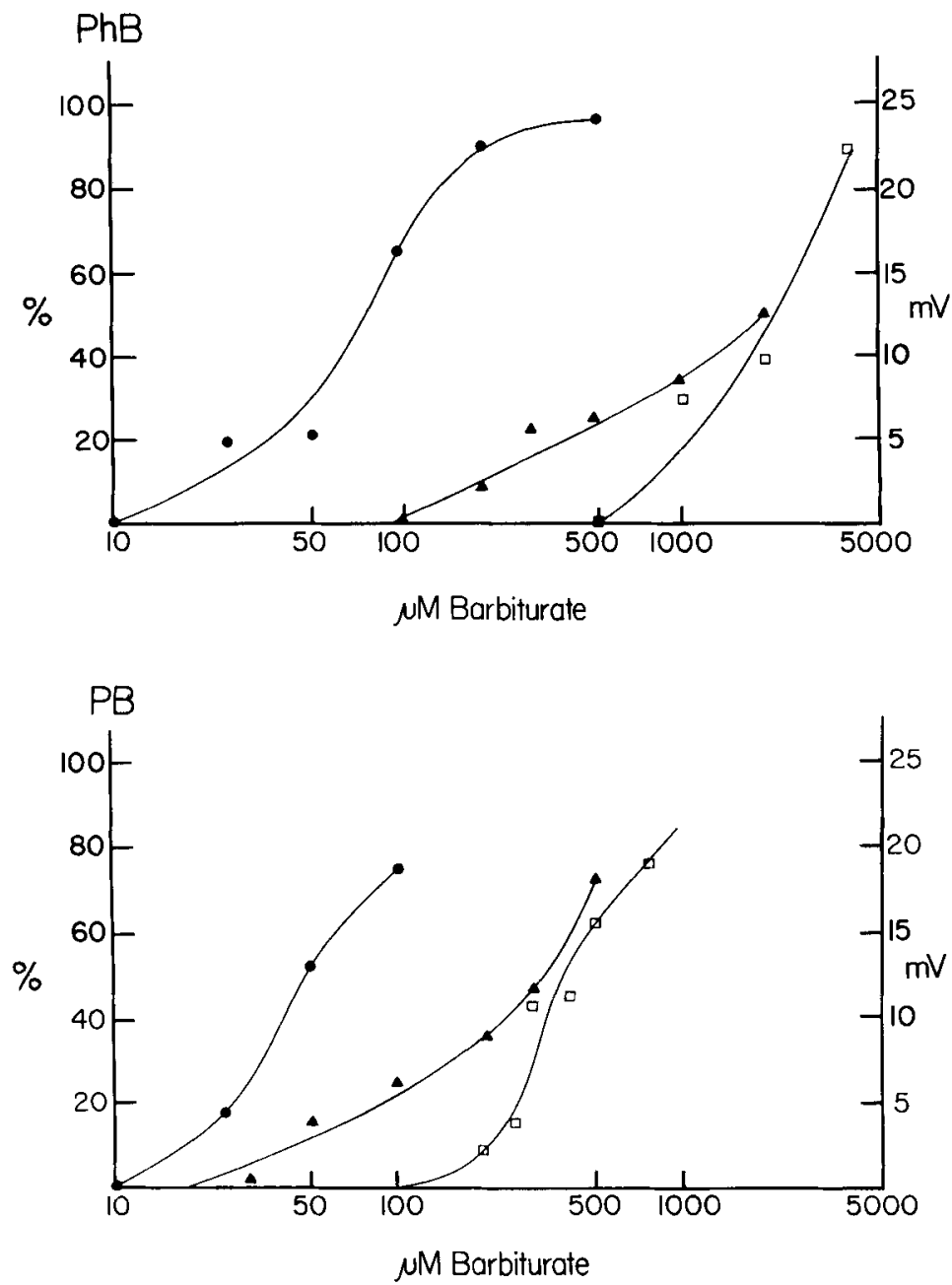

FIG. 4. Dose-dependency of phenobarbital ( $\mathrm{PhB}$, top) and pentobarbital (PB, bottom) enhancement of GABA responses (circles), reduction of calcium-dependent action potentials (triangles), and membrane depolarization $(\mathrm{mV})$ (squares). (From Heyer and Macdonald (39), with permission.) 
chloride ion conductance produced by barbiturates was blocked by the GABA antagonists penicillin and picrotoxin (19), suggesting that the barbiturates bound to GABA receptors. Increasing postsynaptic membrane chloride ion conductance would produce membrane hyperpolarization and a decrease in membrane excitability. $\mathrm{PhB}$ produced these actions only at high concentrations, reducing calcium-dependent action potential duration from 100 to 5,000 $\mu M\left(\mathrm{ED}_{50}, 900 \mu M\right)(39)$ and increasing chloride ion conductance from 500 to 4,000 $\mu M$ (3) (Fig. 4, top). PB was much more potent in both actions, reducing calciumdependent action potential duration from 25 to $600 \mu M\left(\mathrm{ED}_{50}, 170 \mu M\right)$ and increasing chloride ion conductance from 100 to 500 $\mu M$ (Fig. 4 , bottom). For both barbiturates, reduction of calcium-dependent action potential duration and increase in membrane chloride ion conductance correlated with reduction of spontaneous activity (Figs. 1 and 4). From these data, we concluded that sedative-hypnotic actions of barbiturates may be due to slight reduction of neurotransmitter release in addition to modulation of postsynaptic neurotransmitter responses. Anesthesia may be produced by a larger reduction of neurotransmitter release, in addition to modulation of postsynaptic neurotransmitter responses and direct membrane hyperpolarization. Finally, the only difference between anticonvulsant and anesthetic barbiturates is the dosedependency of these actions. PhB has a relatively large therapeutic index between drug concentrations producing postsynaptic modulation of neurotransmitter responses and those producing reduction of presynaptic neurotransmitter release and postsynaptic membrane hyperpolarization (Fig. 4, top). For PB, there is a poor therapeutic index (Fig. 4, bottom).

\section{Phenytoin Actions}

Phenytoin (PT) is useful in the management of a wide variety of partial and generalized seizure types similar to those responsive to phenobarbital. However, PT has less sedative action than the barbiturates. The mechanism of PT anticonvulsant action is unclear. PT limits generalization of seizures without suppressing seizure foci, and thus is unlike barbiturates, which elevate seizure threshold (46). $\mathrm{PT}$ and $\mathrm{PhB}$ also have different effectiveness against seizures produced in experimental animals. PT is effective against maximal electroshock seizures (MES) but ineffective against pentylenetetrazol (PTZ) seizures; $\mathrm{PhB}$ is more effective against PTZ seizures than against MES $(47,48)$. Thus, despite having similar clinical anticonvulsant efficacy, their mechanisms of action are undoubtedly dissimilar.

To investigate the clinically relevant actions of PT it is necessary to determine the concentration of PT in the central nervous system when serum levels are in the therapeutic range. PT is a lipid soluble compound that is highly protein bound $(\sim 90 \%)$. At therapeutic serum levels $(10-20 \mu \mathrm{g} / \mathrm{ml}$ or $40-80 \mu M)$, free-serum PT levels are about $1-2 \mu \mathrm{g} / \mathrm{ml}(4-8 \mu M)$. Cerebrospinal fluid levels are equal to free-serum levels, but brain concentrations are variable and range from 75 to $120 \%$ of total serum concentration (49). Thus, does PT have its relevant actions at total serum, free-serum, or brain concentrations? As one approach to this issue, we determined the dose-dependency of PT actions on spontaneous activity and on convulsant-induced paroxysmal activity recorded from mouse spinal cord neurons in cell culture $(50)$. When added to the protein-free bathing medium, PT did not alter normal spontaneous activity at concentrations up to $2 \mu \mathrm{g} / \mathrm{ml}$ (Fig. 5). However, above $2 \mu \mathrm{g} / \mathrm{ml}$, there was a progressive reduction in spontaneous activity and an increase in the percentage of neurons with no spontaneous activity. At $5 \mu \mathrm{g} / \mathrm{ml}$, about $50 \%$ of neurons were quiescent. Based on these results, it is unlikely that $\mathrm{PT}$ has its clin- 


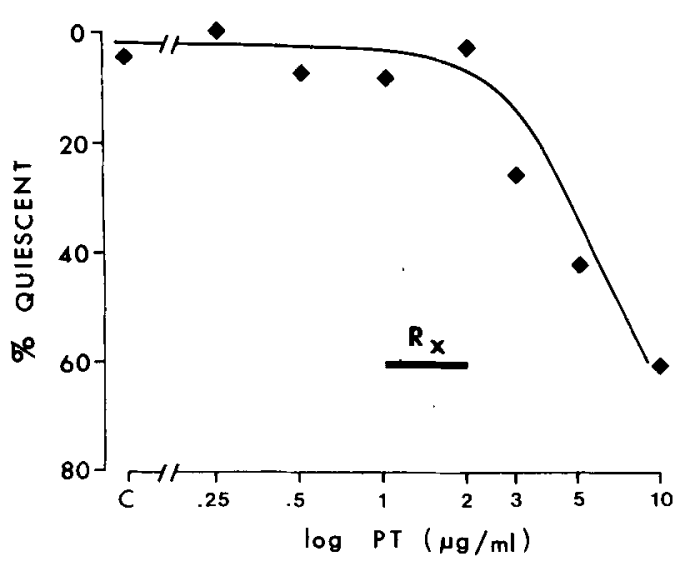

FIG. 5. Phenytoin reduced spontaneous activity. Phenytoin produced a dose-dependent increase in the number of quiescent neurons. However, at or below 2 $\mu \mathrm{g} / \mathrm{ml}$, PT did not alter spontaneous activity.

ical action at brain or total serum concentrations, since all spontaneous activity would be suppressed. Thus, it is likely that the free-serum (and cerebrospinal fluid) levels of $1-2 \mu \mathrm{g} / \mathrm{ml}$ are the relevant concentrations.

If free-serum concentrations of PT are relevant for anticonvulsant action, what effect does PT have on convulsant-induced paroxysmal activity at these concentrations? At $2 \mu \mathrm{g} / \mathrm{ml}$, PT did not suppress PDE
(Fig. 6, top). The paroxysmal activity was often increased in frequency by PT. When higher concentrations of PT were used $(5-20 \mu \mathrm{g} / \mathrm{ml})$, PDE was suppressed in a dose-dependent fashion, but the paroxysmal activity was replaced by quiescence (Fig. 6, bottom). Thus, unlike the barbiturates, PT does not act by suppressing convulsant-induced paroxysmal activity.

How then does PT produce anticonvulsant effects? Four basic actions of PT have been described and proposed as the anticonvulsant mechanism of action (Table 2). First, PT has been shown to reduce the rise in intracellular sodium produced by MES (51). Two alternative mechanisms for this have been proposed. PT and the inactive PT metabolite 5-hydroxyphenyl-5phenylhydantoin (HPPH) enhance Na-K ATPase activity $(52,53)$ (and therefore presumably increase active extrusion of sodium ions) by reducing the inhibitory effect of high sodium concentrations. However, this effect was not specific for PT, since HPPH was also active (53). Thus, it is unlikely that PT has anticonvulsant action by enhancing active sodium extrusion. Alternatively, PT has been shown to reduce the maximal rate of rise, overshoot, and
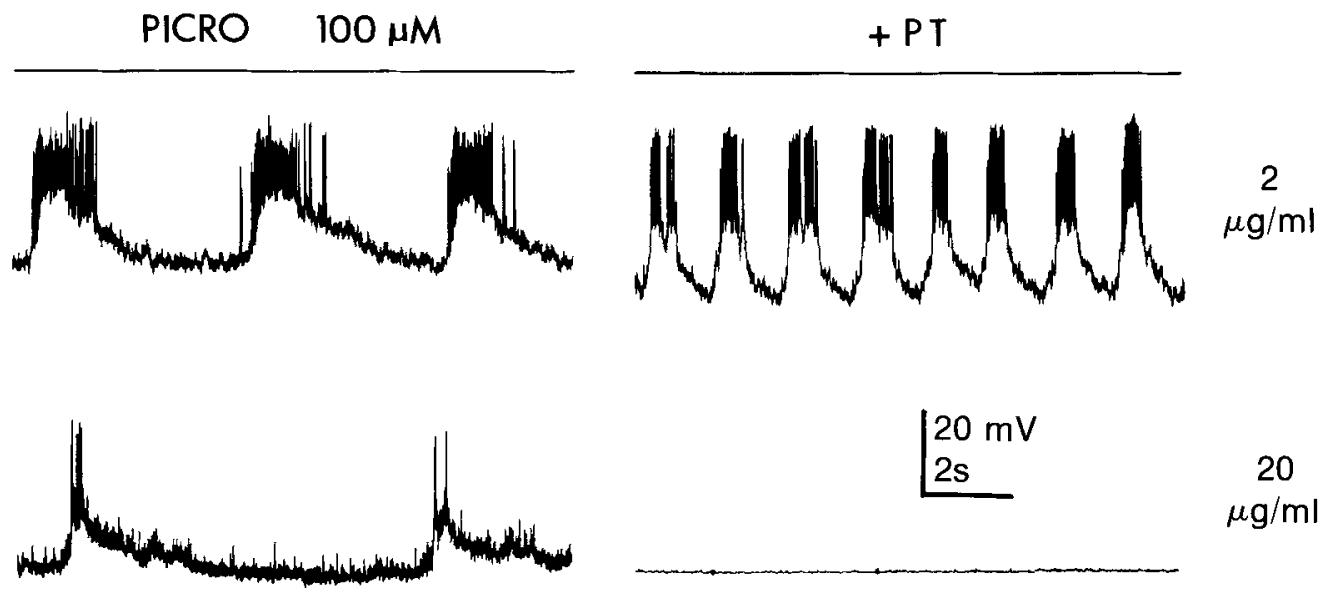

FIG. 6. Phenytoin (PT) did not suppress paroxysmal depolarizing events (PDE) at therapeutic free-serum concentrations. PDE were produced by addition of $100 \mu M$ picrotoxin (PICRO) to phosphate buffered saline bathing medium. PT at $2 \mu \mathrm{g} / \mathrm{ml}$ did not suppress PICRO-induced PDE (top) but did suppress PDE at $20 \mu \mathrm{g} / \mathrm{ml}$ (bottom). Intracellular recordings were made with micropipettes containing $4 M$ potassium acetate. 
TABLE 2. Phenytoin actions

\author{
Reduction of nonsynaptic sodium ion movements \\ Enhancement of active sodium ion transport \\ Reduction of sodium ion channel conductance \\ Reduction of presynaptic calcium ion entry and neurotransmitter release \\ Alteration of postsynaptic neurotransmitter action \\ Enhancement of GABA-mediated inhibition \\ Antagonism of excitatory synaptic trảnsmission \\ Reduction of repetitive firing and posttetanic potentiation
}

amplitude of sodium-dependent action potentials (54-57) and to decrease inward sodium ion fluxes $(58,59)$. Second, PT has been shown to reduce calcium-dependent potentials $(60)$, to reduce inward calcium fluxes $(61-63)$, and to reduce presynaptic release of neurotransmitters (64-67). Third, PT has been shown to modify postsynaptic neurotransmitter responses. PT enhanced postsynaptic GABA responses in the crayfish stretch receptor neuron $(68,69)$ as well as cortical inhibition in the cat (70). However, PT did not alter GABA responses evoked on rat dorsal root ganglion neurons (71) nor on rat hippocampal pyramidal neurons (72). PT reduced excitatory postsynaptic responses to acetylcholine at the neuromuscular junction (67) and the excitatory actions of glutamate and acetylcholine in rat cortex (73). Finally, PT has been shown to reduce repetitive firing (74-76) of neurons, nerve terminals, and muscle cells, and to reduce posttetanic potentiation $(76,77)$ evoked in cat spinal cord and sympathetic ganglia.

Using spinal cord neurons in cell culture, we studied several of these actions of PT to determine which were produced at low PT concentrations $(1-2 \mu \mathrm{g} / \mathrm{ml})(50)$. PT reduced the maximum rate of rise of sodiumdependent action potentials (an index of inward sodium current) and reduced the duration of calcium-dependent action potentials (an index of inward calcium current) only at PT concentrations above $2.5 \mu \mathrm{g} / \mathrm{ml}$. The reduction of action potentials correlated with reduction of spontaneous activity. GABA and glutamate responses were not altered by PT at $2 \mu \mathrm{g} / \mathrm{ml}$. Thus, it is unlikely that PT has anticonvulsant action by blocking sodium channels or calcium channels or by modulating postsynaptic GABA responses. However, repetitive firing produced by depolarizing currents was substantially reduced by PT at $1-2 \mu \mathrm{g} / \mathrm{ml}$ (Fig. 7). In control medium, a 2-s depolarization of sufficient amplitude evokes a continuous train of action potentials. PT at $0.2 \mu \mathrm{g} / \mathrm{ml}$ did not modify this firing pattern (Fig. 7A). However, PT at 1.0 and $2.0 \mu \mathrm{g} / \mathrm{ml}$ reduced the duration of repetitive firing dose-dependently (Fig. 7B and C). HPPH at $10 \mu \mathrm{g} / \mathrm{ml}$ did not modify repetitive firing (Fig. 7D). The effect of PT on repetitive firing was fully reversible following washout of the PT. Thus, PT may have anticonvulsant activity due to its ability to limit high frequency repetitive firing, a characteristic firing pattern in epileptogenic foci. The mechanism by which PT produces this limitation of repetitive firing is uncertain and is currently under investigation. Possibilities include (a) a shift of the voltagedependency of slow inactivation of sodium channels, (b) reduction in the rate of removal of sodium channel inactivation, (c) development of use-dependent sodium channel block, or (d) enhancement or production of a slow outward calcium- or voltagedependent potassium conductance.

\section{Conclusions}

The results obtained thus far suggest that although barbiturates and phenytoin have multiple actions on neuronal membrane properties, electrical excitability, and 

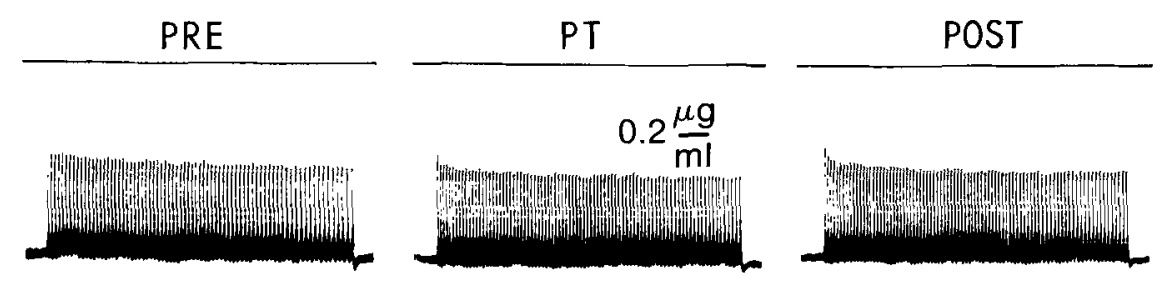

B.
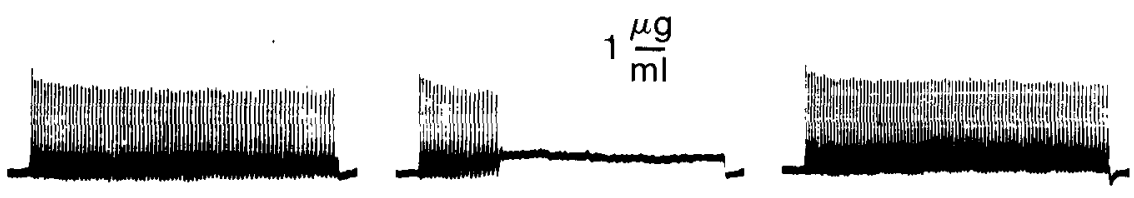

C.
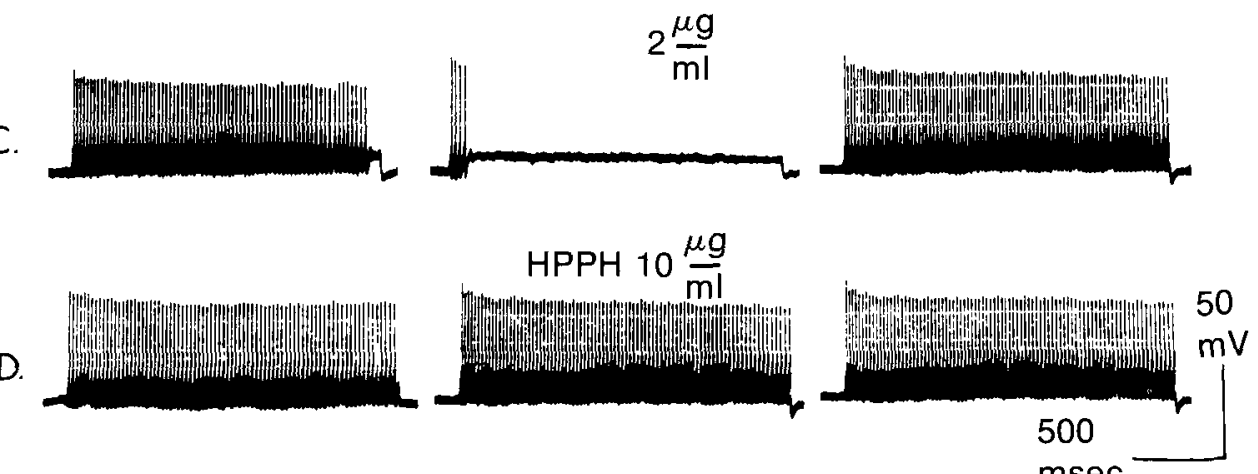

FIG. 7. Phenytoin suppressed repetitive firing. Intracellular recordings were made from spinal cord neurons, and long $(2.0 \mathrm{~s})$ depolarizing current pulses were applied using the single electrode bridge technique. Recordings shown are photographs of oscilloscope traces (A-D). Continuous recordings were made from individual neurons prior to (PRE), during (PT) and following (POST) superfusion of hydantoin-containing bathing medium. The recordings in $A-D$ were made from different neurons. See text for details.

synaptic transmission, their specific anticonvulsant actions can be postulated to be postsynaptic modulation of neurotransmitter actions and suppression of repetitive firing, respectively. These conclusions should be considered as working hypotheses to be evaluated using more intact, vertebrate, central neuronal preparations such as hippocampal or neocortical slices in vitro or intact cortex in vivo. It is certainly possible that alternate mechanisms will be identified in the more intact preparations, but the investigation should be facilitated by comparisons to data obtained from mammalian neurons in cell culture.

A clear objective of this research in the future is the identification of the therapeutic and toxic actions of all major anticonvulsants using this in vitro preparation. Once these mechanisms are identified, it should be possible to study specific physiological actions of drug congeners to identify which portions of the drug molecules are relevant for each of the therapeutic and toxic drug actions. Furthermore, it should be possible to formulate specific drugs that would have improved therapeutic indices and therefore would be clinically more useful. Finally, it should be possible to study the interactions of anticonvulsants with different mechanisms of action to determine which drugs have synergistic anticonvulsant action without synergistic toxicity.

\section{References}

1. Nelson PG, Neale EA, Macdonald RL. Electrophysiological and structural studies of neurons in dissociated cell cultures of the central nervous system. In: Nelson PG, Lieberman M, eds. Excit- 
able cells in tissue culture. New York: Plenum Press, 1980:50-80.

2. Macdonald RL, Barker JL. Neuropharmacology of spinal cord neurons in primary dissociated cell culture. In: Nelson PG, Lieberman M, eds. Excitable cells in tissue culture. New York: Plenum Press, 1980:81-109.

3. Schulz DW, Macdonald RL. Barbiturate enhancement of GABA-mediated inhibition and activation of chloride ion conductance: correlation with anticonvulsant and anesthetic actions. Brain Res $1981 ; 209: 177-88$.

4. Curtis DR, Duggan AW, Felix D, Johnston GAR. Bicuculline, an antagonist of GABA and synaptic inhibition in the spinal cord of the cat. Brain Res 1971:32:69-96.

5. Macdonald RL, Barker JL. Specific antagonism of GABA-mediated postsynaptic inhibition in cultured mammalian spinal cord neurons: a common mode of convulsant action. Neurology (NY) 1978:28:325-30.

6. Nowak LM, Young AB, Macdonald RL. GABA and bicuculline actions on mouse spinal cord and cortical neurons in cell culture. Brain Res 1982; 244: 155-64.

7. Enna SJ, Snyder SH. Properties of $\gamma$ aminobutyric acid (GABA) receptor binding in rat brain synaptic membrane fractions. Brain Res 1975;100:81-97

8. Frere RC, Macdonald RL, Young AB. GABA binding and bicuculline in spinal cord and cortical membranes from adult rat and from mouse neurons in cell culture. Brain Res 1982;244:145-54.

9. Heyer EJ, Nowak LM, Macdonald RL. Bicuculline: a convulsant with synaptic and nonsynaptic actions. Neurology ( $N Y$ ) 1981:31:1381-90.

10. Heyer EJ, Nowak LM, Macdonald RL. Membrane depolarization and prolongation of calcium-dependent action potentials of mouse neurons in cell culture by two convulsants: bicuculline and penicillin. Brain Res 1982;232: $41-56$.

11. Schwindt $P$, Crill $W$. Role of a persistent inward current in motoneuron bursting during spinal seizures. J Neurophysiol 1980;43:1296-1318.

12. Matsumoto $\mathrm{H}$, Marsan CA. Cortical cellular phenomena in experimental epilepsy: interictal manifestations. Exp Neurol 1964;9:286-304.

13. Prince DA. Neurophysiology of epilepsy. Ann Rev Neurosci 1978;1:395-415.

14. Schmidt RF. Presynaptic inhibition in the vertebrate central nervous system. Ergeb Physiol Biol Chem Exp Pharmakol 1971;63:20-101.

15. Nicoll RA. Pentobarbital: action of frog motoneurons. Brain Res 1975;96:119-23.

16. Polc P, Haefely W. Effects of two benzodiazepines, phenobarbitone, and baclofen on synaptic transmission in cat cuneate nucleus. Naunyn Schmiedebergs Arch Pharmacol 1976; 294:121-31.

17. Barker JL, Ransom BR. Amino acid pharmacology of mammalian central neurones grown in tissue culture. $J$ Physiol (Lond) 1978:280:331-54.
18. Macdonald RL, Barker JL. Enhancement of GABA-mediated postsynaptic inhibition in cultured mammalian spinal cord neurons: a common mode of anticonvulsant action. Brain Res 1979;167:323-36.

19. Macdonald RL, Barker JL. Anticonvulsant and anesthetic barbiturates: different postsynaptic actions on cultured mammalian neurons. Neurology (NY) 1979;29:432-47.

20. Adams PR. Drug blockade of open end-plate channels. J Physiol 1976;260:531-52.

21. Nicoll RA, Iwamoto ET. Action of pentobarbital on sympathetic ganglion cells. J Neurophysiol 1978;41:977-86.

22. Brooks CM, Eccles JC. A study of the effects of anaesthesia on the monosynaptic pathway of the spinal cord. J Neurophysiol 1947;10:349-60.

23. Somjen GC, Gill M. The mechanism of the blockade of synaptic transmission in the mammalian spinal cord by diethyl ether and by thiopental. $J$ Pharmacol Exp Ther 1963;140:19-30.

24. Løyning Y, Oshima T, Yokota J. Site of action of thiamytal sodium on the monosynaptic spinal reflex pathway in cats. J Neurophysiol 1964; 27:408-28.

25. Weakly JN. Effect of barbiturates on "quantal' synaptic transmission in spinal motoneurons. $J$ Physiol 1969:204:63-77.

26. Cutler RWP, Markowitz D, Dudzinski DS. The effect of barbiturates on $\left[{ }^{3} \mathrm{H}\right] \mathrm{GABA}$ transport in rat cerebral cortex slices. Brain Res 1974;81: 189-97.

27. Cutler RWP, Young J. Effect of barbiturates on release of endogenous amino acids from rat cortex slices. Neurochem Res 1979;4:319-29.

28. Waller MB, Richter JA. Effects of pentobarbital and $\mathrm{Ca}^{2+}$ on the resting and $\mathrm{K}^{+}$-stimulated release of several endogenous neurotransmitters from rat midbrain slices. Biochem Pharmacol 1980;29: 2189-98.

29. Potashner SJ, Lake N, Langlois EA, Plouffe L Jr, Lecavalier D. Pentobarbital: differential effects on the depolarization-induced release of exictatory and inhibitory amino acids from cerebral cortex slices. Brain Res Bull 1980;5:659-64.

30. Willow M, Bornstein JC, Johnston GAR. The effects of anaesthetic and convulsant barbiturates on the efflux of $\left[{ }^{3} \mathrm{H}\right]$-D-asparate from brain minislices. Neurosci Lett 1980;18:185-90.

31. Kalant H, Grose W. Effects of ethanol and pentobarbital on release of acetylcholine from cerebral cortex slices. I Pharmacol Exp Ther 1967:158:386-95.

32. Richter JA, Waller W. Effects of pentobarbital on the regulation of acetylcholine content and release in different regions of rat brain. Biochem Pharmacol 1977:26:609-15.

33. Richter JA, Werling LL. K-stimulated acetylcholine release: inhibition by several barbiturates and chloral hydrate but not by ethanol, chlordiazepoxide or 11-OH-9-tetrahydrocannabinol. $J$ Neurochem 1979;32:935-41.

34. Lindmar R, Löffelholz K, Weide W. Inhibition by 
pentobarbital of the acetylcholine release from the postganglionic parasympathetic neuron of the heart. I Pharmacol Exp Ther 1979;210:166-73.

35. Haycock JW, Levy WB, Cotman CW. Pentobarbital depression of stimulus-secretion coupling in brain-selective inhibition of depolarizationinduced calcium-dependent release. Biochem Pharmacol 1977:26:159-61.

36. Blaustein MP. Barbiturates block sodium and potassium conductance increases in voltageclamped lobster axons. J Gen Physiol 1968;51: 293-307.

37. Narahashi T, Frazier DT, Deguchi T, Cleaves CA, Enau M. The active form of pentobarbital in squid giant axons. I Pharmacol Exp Ther $1971 ; 177: 25-33$.

38. Schwarz JR. The mode of action of phenobarbital on the excitable membrane of the node of Ranvier. Eur J Pharmacol 1979;56:51-60.

39. Heyer EJ, Macdonald RL. Barbiturate reduction of calcium-dependent action potentials: correlation with anesthetic action. Brain Res 1982; 236: $157-71$.

40. Fatt $P$, Katz B. Spontaneous subthreshold activity at motor nerve endings. J Physiol 1952:117: 109-28.

41. Katz B, Miledi R. A study of synaptic transmission in the absence of nerve impulses. I Physiol 1967;192:407-36.

42. Katz B, Miledi R. Tetrodotoxin-resistant electric activity in presynaptic terminals. $J$ Physiol 1969;203:459-87.

43. Blaustein MP, Ector AC. Barbiturate inhibition of calcium uptake by depolarized nerve terminals in vitro. Mol Pharmacol 1975;11:369-78.

44. Blaustein MP. Barbiturates block calcium uptake by stimulated and potassium-depolarized rat sympathetic ganglia. I Pharmacol Exp Ther 1976; 196:80-6.

45. Ondrusek MG, Belknap JK, Leslie SW. Effects of acute and chronic barbiturate administration on synaptosomal calcium accumulation. Mol Pharmacol 1979;15:386-95.

46. Woodbury DM. Mechanism of action of anticonvulsants. In: Jasper $\mathbf{H}$, Ward A, Pope A, eds. Basic mechanisms of the epilepsies. Boston: Little, Brown, 1969:647-81.

47. Swinyard EA, Brown WC, Goodman LS. Comparative assays of antiepileptic drugs in mice and rats. J Pharmacol Exp Ther 1952;106:47-59.

48. Goodman LS, Swinyard EA, Brown WC, Schiffman DO, Grewal MS, Bliss EL. Anticonvulsant properties of 5-phenyl-5-ethyl-hexahydropyrimidine-4,6-dione (Mysoline), a new antiepileptic. $J$ Pharmacol Exp Ther 1953;108:428-36.

49. Sironi VA, Cabrini G, Porro MG, Ravagnati L, Marossero F. Antiepileptic drug distribution in cerebral cortex, Ammon's horn, and amygdala. $J$ Neurosurg 1980;52:686-92.

50. McLean MJ, Macdonald RL. Phenytoin effects on action potentials of fetal mouse spinal cord neurons in cell culture. Soc Neurosci Abstr $1981 ; 7: 629$.
51. Woodbury DM. Effect of diphenylhydantoin on electrolytes and radiosodium turnover in brain and other tissues of normal, hyponatremic and postictal rats. J Pharmacol Exp Ther 1955;115: 74-95.

52. Festoff BW, Appel SH. Effect of diphenylhydantoin on synaptosome sodium-potassium ATPase. $J$ Clin Invest 1968;47:2752-8.

53. Siegel GJ, Goodwin BB. Sodium-potassiumactivated adenosine triphosphatase of brain microsomes: modification of sodium inhibition by diphenylhydantoin. J Clin Invest 1972;51:1164-9.

54. Lipicky RJ, Gilbert DL, Stillman IM. Diphenylhydantoin inhibition of sodium conductance in squid giant axon. Proc Natl Acad Sci USA 1972:69:1758-60.

55. Schwarz J, Vogel W. Diphenylhydantoin: excitability reducing action in single myelinated nerve fibres. Eur J Pharmacol 1977:44:241-9.

56. Neuman RS. Frank GB. Effects of diphenylhydantoin and phenobarbital on voltage-clamped myelinated nerve. Can J Physiol Pharmacol 1977;55:42-7.

57. Selzer ME. The effect of phenytoin on the action potential of a vertebrate spinal neuron. Brain Re's 1979:171:511-21.

58. Perry JG, McKinney L, DeWeer P. The cellular mode of action of the antiepileptic drug 5,5diphenylhydantoin. Nature 1978;272:271-3.

59. Ferrendelli JA, Kinscherf DA. Similar effects of phenytoin and tetrodotoxin on cyclic nucleotide regulation in depolarized brain tissue. I Pharmacol Exp Ther 1978;207:787-93.

60. Tuttle JB, Richelson E. Phenytoin action on the excitable membrane of mouse neuroblastoma. $J$ Pharmacol Exp Ther 1979;211:632-7.

61. Sohn RS, Ferrendelli JA. Inhibition of $\mathrm{Ca}^{++}$transport into rat brain synaptosomes by diphenylhydantoin. I Pharmacol Exp Ther 1973;185: 272-5.

62. Hasbani M, Pincus J, Lee SH. Diphenylhydantoin and calcium movement in lobster nerves. Arch Neurol 1974;31:250-4.

63. Study RE. Phenytoin inhibition of cyclic guanosine $3^{\prime}-5^{\prime}$-monophosphate (cGMP) accumulation in neuroblastoma cells by calcium channel blockade. I Pharmacol Exp Ther 1980;215:575-81.

64. Pincus JH, Lee SH, Diphenylhydantoin and calcium: relation to norepinephrine release from brain slices. Arch Neurol 1973;29:239-44.

65. Carnay L, Grundfest S. Excitable membrane stabilization by diphenylhydantoin and calcium. Neuropharmacology 1974;13:1097-108.

66. Yarri Y, Pincus JH, Argov Z. Depression of synaptic transmission by diphenylhydantoin. Ann Neurol 1977;1:334-8.

67. Gage PW, Lonergan M, Torda TA. Presynaptic and postsynaptic depressant effects of phenytoin sodium at the neuromuscular junction. $B r J$ Pharmacol 1980;69:119-21.

68. Ayala GF, Johnston D, Lin S, Dichter HN. The mechanism of action of diphenylhydantoin on in- 
vertebrate neurons. II. effects on synaptic mechanisms. Brain Res 1977;121:259-70.

69. Deisz RA, Lux HD. Diphenylhydanıoin prolongs postsynaptic inhibition and iontophoretic GABA action in the crayfish stretch receptor. Neurosci Lett 1977:5:199-203.

70. Raabe W, Ayala GF. Diphenylhydantoin increases cortical postsynaptic inhibition. Brain Res 1976:105:597-601.

71. Connors BW. A comparison of the effects of pentobarbital and diphenylhydantoin on the GABA sensitivity and excitability of adult sensory ganglion cells. Brain Res 1981;207:357-69.

72. Hershkowitz N, Ayala GF. Effects of phenytoin on pyramidal neurons of the rat hippocampus. Brain Res 1981;208:487-92.

73. Sastry SR, Phillis JW. Antagonism of glutamate and acetylcholine excitation of rat cerebral cortical neurons by diphenylhydantoin. Gen Pharmacol 1976;7:411-3.

74. Toman JEP. The neuropharmacology of antiepileptics. Electroenceph Clin Neurophysiol 1949;1:33-44.

75. Korey SR. Effect of dilantin and mesantoin on the giant axon of the squid. Proc Soc Exp Biol Med 1951:76:297-9.

76. Raines A, Standaert FG. An effect of diphenylhydantoin on post tetanic hyperpolarization of intramedullary nerve terminals. J Pharmacol Exp Ther 1967;156:591-7.

77. Esplin D. Effect of diphenylhydantoin on synaptic transmission in the cat spinal cord and stellate ganglion.J Pharmacol Exp Ther 1957;120: 301-23. 